\title{
EFFECT OF COOLING IN A FABRICATED SOLAR COOLER ON HISTOLOGY OF PANGASIUS (PANGASIANODON HYPOTHALAMUS) MUSCLE ${ }^{\dagger}$
}

\author{
O. BISWAS ${ }^{1 *}$, P. KANDASAMY ${ }^{1}$ AND P. SARKAR ${ }^{2}$ \\ ${ }^{1}$ Department of Agricultural Engineering, Palli Siksha Bhavana (Institute of Agriculture), Visva Bharati, \\ Sriniketan-731 236, West Bengal, India \\ ${ }^{2}$ Department of Livestock Products Technology, West Bengal University of Animal \& Fishery \\ Sciences, Kolkata-700 037, West Bengal, India
}

\begin{abstract}
The present study was conducted to study the histology of Pangasius (Pangasianodon hypothalamus) muscle by keeping it in the fabricated solar cooler maintaining the temperature at $\left(5^{\circ} \mathrm{C} \pm 1^{\circ} \mathrm{C}\right)$ for the very first time. The fillets were packed in low-density polyethylene and were stored. One portion was analysed on the 0 day and the remaining portions were analysed after keeping those samples in the chilling storage on $3^{\text {rd }}, 7^{\text {th }}, 15^{\text {th }}$ and $30^{\text {th }}$ day to determine the histological changes of the fish muscle relating to its structural integrity. The micro- sections were stained by haematoxylin and eosin for microscopic examination under compound microscope at 10x magnification. Histological changes revealed significant changes in preserved muscle structure. On $3^{\text {rd }}$ day of storage $\left(5^{\circ} \mathrm{C} \pm 1^{\circ} \mathrm{C}\right)$ the muscle fibres were separated by small intracellular spaces and the nucleus retained the haematoxylin-eosin stain. Bending or kinking of the fibres was less distinct at this instant. On $7^{\text {th }}$ day onward, the changes of solar cooled fish muscle were comparatively more distinct up to $3^{\text {th }}$ day. Such structural disintegration would have a special significance to explain other qualitative attributes of such muscles as noted in different works.
\end{abstract}

Key words: Histology, Pangasius, Solar cooler

Globally, there is a great demand for food preservation due to the obvious reason of mitigating the food scarcity, quality and safety, and particularly in respect to provide fresh food to the consumer. In India, there is a great demand for food preservation for providing fresh and wholesome food. By lowering the temperature, the shelf-life of the food products can be increased effectively as the growth of the spoilage microbes are slowed down. As such, due to low microbial and enzymatic activity, food products can sustain their textural and nutritional quality for a considerable period of time. But this low temperature preservation can cause some negative impact on the food products such as release of free acids (Leygonie et al., 2012) and disintegration of muscle structure and texture resulting lowering of nutritional quality as observed through enhancement of drip loss etc (Kandeepan et al., 2006). Considering this, it is important to know the exact period of keeping for such perishable products in a low temperature visa-vice their structural disintegrations. In many parts of India, maintaining the quality of perishable protein valued food items viz. meat, fish, and milk is a challenge, as there is an inconsistent electricity

*Corresponding Author

'Part of Ph.D Thesis work of the First Author 
supply and conventional fuels are costly or difficult to obtain. One of the conventional food preservation systems is refrigeration, which needs electricity and also works under different freonsemission (Thirugnanasambandam et al., 2010), often causes depletion of ozone layers and produces greenhouse gases like $\mathrm{CO}_{2}, \mathrm{NO}_{2}$ etc. Use of solar energy, a promising proposition and an alternate unconventional energy sources, is on the demand because of the growing necessity on energy along with high oil prices and concerns of environmental impacts. Solar is the energy obtained from sun rays through convertible technology called photovoltaic (PV) cells, which converts sunlight directly into electricity. This produced electricity in turn used for refrigeration. Till date no such environment friendly and cheap cooler system in a form of a cooler box is readily available to preserve fish or meat products particularly in Indian market. Here such system has been fabricated and explored to be used for the purpose of short-term preservation.

Pangasianodon hypothalamus also known as sutchi catfish is a riverine freshwater fish, usually processed to frozen fillets for household consumptions. The histological characteristics of this fish muscle are very regular. Muscle fibers are the main structural and functional unit. The myofibrils as subunits of the fibre are located longitudinally and in parallel to each other. The remaining part of the muscle fibre is made up of sarcoplasm, sarcolemma and nuclei (Dong et al., 2017). Absence of fishy odor, tender and white flesh, firm cooked texture and high nutritive value with easily digestible proteins and excellent sensory attributes have expanded its consumer preference (Wang and Hsieh, 2016). The fishbased products have a great consumer demand especially ready-to-eat convenient products due to socio-cultural changes (Rathod and Pagarkar, 2013) and these fish fillets were selected for the present study considering its ever increasing importance to the fish consumers. Strateva and Penchev (2020) had also discussed the importance of histological changes in fish muscles in cold preservation and considered as one of the tools to highlight the status of the fish muscle in order to its acceptability to the consumers.

In the present study solar cooler is developed by using solar energy following the specific protocol of using Peltier module in thermocouple (Jugsujinda et al., 2011) and the fish fillets were kept in the cooler for 30 days with maintaining the temperature $5^{\circ} \mathrm{C} \pm 1^{\circ} \mathrm{C}$. Staining micro sections with haematoxylin and eosin, the microscopic study was conducted to find out the histological changes in fish muscle portions in different interval of days $\left(0,3^{\text {rd }}, 7^{\text {th }}, 15^{\text {th }}\right.$, and $\left.30^{\text {th }}\right)$.

\section{MATERIALS AND METHODS}

Fabrication of solar cooler: The fabricated solar cooler in this study is shown in Fig. 1. The cooling chamber was made from food grade plastic material with volume of $25000 \mathrm{cc}$ and with proper provision of insulating foam with $1 \mathrm{~cm}$ thickness. Two heat sinks, made up of aluminum finned radiators were fixed inside (size $4 \mathrm{~cm} \times 4 \mathrm{~cm} \times$ $2.6 \mathrm{~cm}$ ) and outside (size $10 \mathrm{~cm} \times 10 \mathrm{~cm} \times 3 \mathrm{~cm}$ ) the cooling chamber. The heat sinks helped to absorb and dissipate heat from the cooling chamber into the atmosphere for the purpose of making the chamber cool. Two inbuilt small fans $(12 \mathrm{~V}, 0.28 \mathrm{~A})$ were fitted with heat sink to remove heat from the cooling chamber. Heat transfer takes place from the chamber through a module called thermoelectric module (TM) which is a solid-state heat pump that functions on the principle of heat conductivity called 'Peltier's effect'. In the fabricated cooling chamber here the TM has a capacity of $12 \mathrm{~V}, 50 \mathrm{~W}$. A battery $(12 \mathrm{~V}, 10 \mathrm{~A}, 10 \mathrm{Hrs}$, size $15.11 \mathrm{~cm} \times 10.92 \mathrm{~cm} \times 6.35$ $\mathrm{cm})$ was used. In this solar cooler, one polycrystalline type solar panel $(12 \mathrm{~V}, 80 \mathrm{~W}$, size: $77.8 \mathrm{~cm} \times 69 \mathrm{~cm} \times 3 \mathrm{~cm}$ ) was used.

Raw material and chemicals: Fresh whole Pangasius fish was procured from local market of Bolpur and brought immediately (a period of 15-20 minutes) to the laboratory of the Department of Agricultural Engineering, Institute of Agriculture, Visva Bharati, West Bengal by 
Indian Journal of Animal Health, June, 2020

Histological Changes of Fish Muscle in Solar Cooler

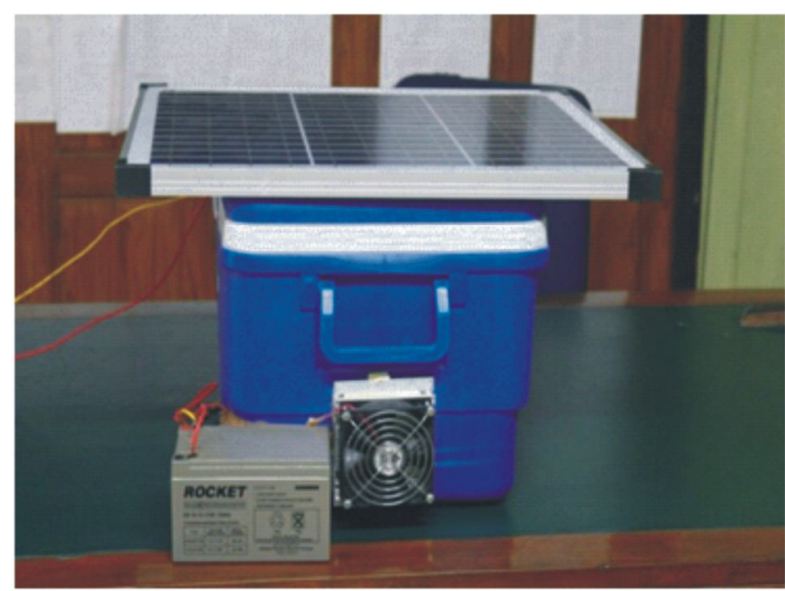

Fig. 1. Fabricated solar cooler

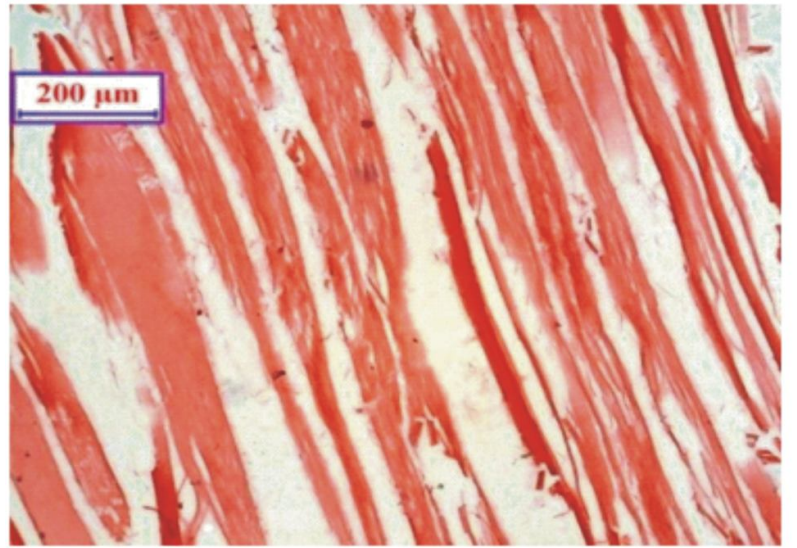

Fig. 3. Histological changes at $3^{\text {rd }}$ day in solar cooler $\left(5^{\circ} \mathrm{C} \pm 1^{\circ} \mathrm{C}\right)$, resolution at $10 \mathrm{x}$

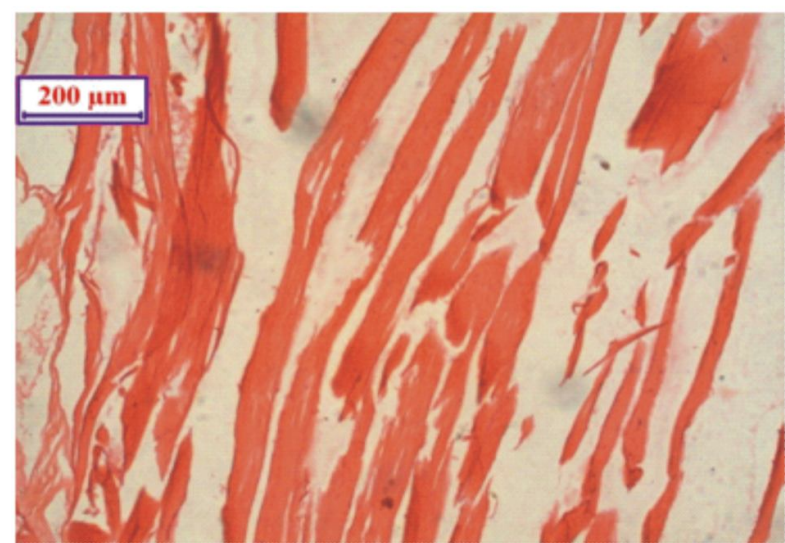

Fig. 5. Histological changes at $15^{\text {th }}$ day in solar cooler $\left(5^{\circ} \mathrm{C} \pm 1^{\circ} \mathrm{C}\right)$, resolution at $10 \mathrm{x}$

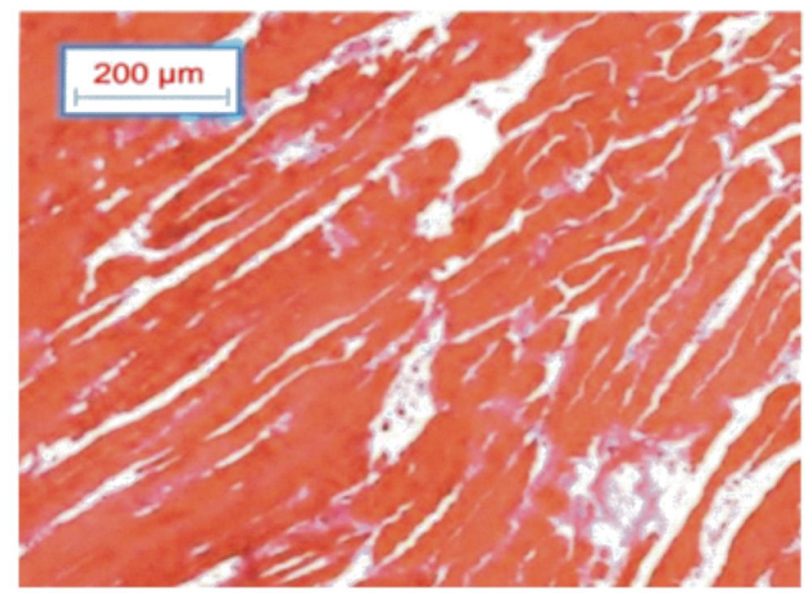

Fig. 2. Normal histology at 0 day, resolution at $10 x$

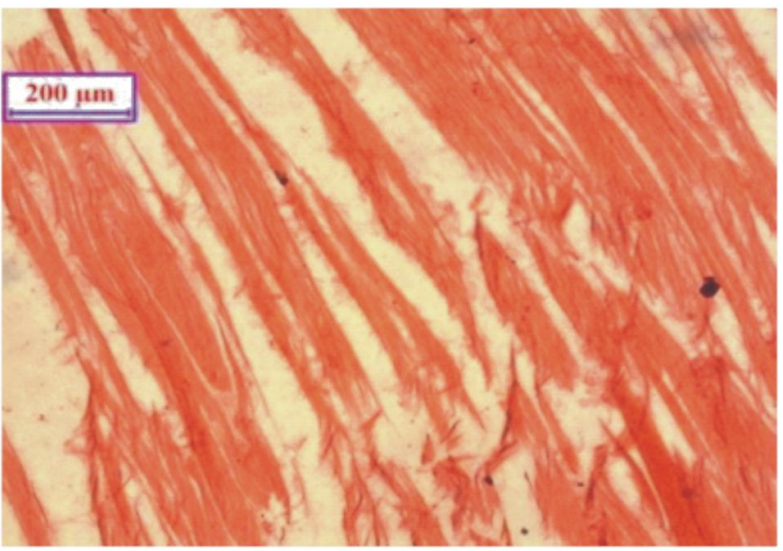

Fig. 4. Histological changes at $7^{\text {th }}$ day in solar cooler $\left(5^{\circ} \mathrm{C} \pm 1^{\circ} \mathrm{C}\right)$, resolution at $10 \mathrm{x}$

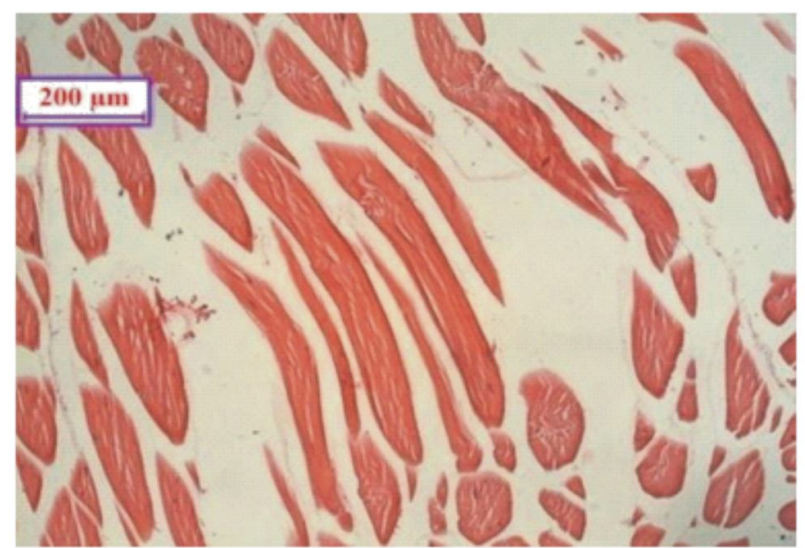

Fig. 6. Histological changes at $30^{\text {th }}$ day in solar cooler $\left(5^{\circ} \mathrm{C} \pm 1^{\circ} \mathrm{C}\right)$, resolution at $10 \mathrm{x}$ 
using ice flakes in an insulated box maintaining cold-chain. The fishes were washed thoroughly in running water, scaled, beheaded, gutted, filleted by standard procedure and washed again. The fish fillets samples weighing $0.5 \mathrm{~kg}$ in total were packaged in low-density polyethylene, where the fillets were divided equally into five groups $\left(0^{\text {th }}, 3^{\text {rd }}, 7^{\text {th }}, 15^{\text {th }}\right.$ and $30^{\text {th }}$ days $)$ each contained $100 \mathrm{~g}$ of fish sample. The samples were stored in solar chiller at $\left(5^{\circ} \mathrm{C} \pm 1{ }^{\circ} \mathrm{C}\right)$. On the respective days the samples were taken out for histological observation following the procedure as described below.

Microscopic procedure: Fresh and chilled fish samples with the thickness of $0.5 \mathrm{~mm}$ were fixed for 48 hours in $10 \%$ formal saline. The tissues which are fixed in formal saline were processed and embedded in paraffin blocks. The paraffin sections of having the thickness of 4-5 $\mu$ were cut by means of conventional methods (Kandeepan et al., 2006).

The histological tissue making procedure was outlined with collection of sample, fixation, washing, dehydration, cleaning of tissue, tissue filtration, block making and section preparation (Luna, 1968). After section preparation, the tissue stained with haematoxylin and eosin stain following the procedure which included as hydration of tissue section, staining, washing, dehydration and mounting as described by Luna, 1968. The micro sections were examined under compound microscope in 10x magnification and photographs were taken of the respective samples on different days for interpretation.

\section{RESULTS}

In the present study, the histological structure of the fish muscle was observed and found that the myocommata were arranged parallel to each other obliquely and the gaps between the muscles were less on 0 day (Fig. 2). The histological structure of the fresh fish fillets were more compact structurally and underwent a noticeable histological changes on subsequent storage period of $3^{\text {rd }}$ day onward in fabricated solar cooler (Fig. 1). After $3^{\text {rd }}$ day of storage, the muscle fibres were separated by small intracellular spaces and the nucleus retained the haematoxylin and eosin stain $(\mathrm{H} \& \mathrm{E}$ stain) and bending or kinking of the muscle fibres were less distinct (Fig. 3). On $7^{\text {th }}$ day, the changes of chilled fish meat were comparatively greater than $3^{\text {rd }}$ day chilled muscles (Fig. 4). On $15^{\text {th }}$ day, breakage in transverse muscles along with longitudinal spaces were noticed. Separation of the muscle fibres was also observed (Fig. 5). More scattered and torn muscle fibres were observed in $30^{\text {th }}$ day of chilled fish fillets (Fig. 6). The gaps between the muscle fibres were more prominent with the prolongation of storage period from 0 day to $30^{\text {th }}$ day.

\section{DISCUSSION}

The histological changes as observed in fish fillets of Pangasius (Pangasianodon hypothalamus) in different days in compare to 0 day observation clearly showed disintegration of fish muscle fibers and it continued to enhance with the period of prolongation under low temperature in solar cooler. These changes were in conformity with the observation of Kandeepan et al. (2006), where they were in opinion that this disintegration might be due to the fact that in low temperature preservation beyond $5^{\circ} \mathrm{C}$, there was transverse breakage of the muscle fibers as a result of physical stress produced by contraction and by the action of autolytic enzymes. Such results were in buffalo muscle. In fish muscles as observed in the present study, it was more pronounced as fish muscle naturally possessed less amount of connective tissues (Strateva and Penchev, 2020) and such connective tissues were primarily responsible to maintain rigidity of muscle structure and texture. Fish muscle had the character of such low content of connective tissue as a peculiar nature, in compare to any other edible muscle sources. Less connective tissue might be the reason of such major disintegration and fragmentation of fish muscle fibers (Strateva and Penchev, 2020). The present observation on histological changes of fish muscle further be explained with the observation of Popelka et al. (2014), where they were in view that muscle structure changed during low temperature storage 
because of the contraction of muscle fibers which caused water molecules to move in the intracellular spaces and created increment in osmotic pressure in subsequent days of storage. The above observation further be explained with the findings of Pirestani et al., 2010 where they had categorized the reasons of cellular decay for such disintegration of several fish muscle fibers in subsequent days of preservation in cool temperature as observed in the present study also. The observation of the histological changes in fish muscles stored in the solar cooler up to 3 days showed that there were no such major changes in the endomysium and perimysium layers of the fish muscles. Major damages and disruptions were absent in the muscle fibers. Myofibers of the muscles were compact and no such difference between muscle fibers was seen. Some minor changes classified as artifacts were seen in the microscopic structures (Strateva and Penchev, 2020). These observations were also noticed in the present study. In a similar work, conducted by Tinacci et al. (2018), on histological discrimination of fresh and cold stored white meat of fishes (Merluccius merluccius species), observed disintegration of muscle structures with progressive days of cold storage preservation justifying the importance of histological changes in cold-stored fishes.

Due to the low temperature i.e. $5^{\circ} \mathrm{C} \pm 1^{\circ} \mathrm{C}$, a phenomenon called cold shortening might have also taken place. This caused tough texture with more gaping. The fish muscle contracted and could not stretch again because the low activity of calcium related enzyme which could not function properly (Zhang et al., 2017) in the ground of modified cellular disintegrated

\section{REFERENCES}

Dong X, Wu Q, Li D, Wang T, Pan J et al., 2017. Physicochemical, micro-structural, and textural properties of different parts from farmed common carp (Cyprinus carpio). Int J Food Properties, 20(4): 946-955 muscle fibers. Similar observation was also notice by Li et al. (2016) in their study on comparative studies of quality changes in muscles of Cyprinus carpio during storage in refrigeration $\left(4^{\circ} \mathrm{C}\right)$. The similar explanation seemed to be very pertinent in the context of present study where the structural disintegrations were similar. Therefore the results received in other works relating to nutritional, microbiological and biochemical aspects would have ample chances of similarity (Gandotra et al., 2012). As the present work had remained restricted with the changes of histological aspects only, the scope of dealing other relevant aspects remained unexplained.

The results clearly showed that the fabricated solar cooler could be a promising aid for short time, and a cheap method of fish and fish products preservation without much deterioration in muscle architecture as observed through histological focusing where "green energy" was utilized. It is more important particularly for the areas where the presence of conventional energy resource is still remote and sometimes not available.

\section{ACKNOWLEDGMENT}

The authors acknowledge the help and facilities received from the Department of Agricultural Engineering, Palli Siksha Bhavana (Institute of Agriculture), Visva Bharati; Department of Livestock Products Technology and Prof. P. Das, Department of Veterinary Anatomy, West Bengal University of Animal \& Fishery Sciences, Kolkata for completion of this present work. The work was supported financially by DST, Govt. of India through Inspire Fellowship (DST/INSPIRE Fellowship/ IF170433) to the first author.

Gandotra R, Sharma S, Koul M and Gupta S, 2012. Effect of chilling and freezing on Fish Muscle. J Pharmacy Biol Sci, 2: 05-09

Jugsujinda S, Vora-ud A and Seetawan T, 2011. 
Analyzing of thermoelectric refrigerator performance. Procedia Engineering, 8: 154159

Kandeepan G, Biswas S and Porteen K, 2006. Influence of histological changes of refrigerator preserved buffalo meat on quality characteristics. J Food Technol, 4(2): 116-121

Li Q, Li D, Qin N, Hong H and Luo Y, 2016. Comparative studies of quality changes in white and dark muscles from common carp (Cyprinus carpio ) during refrigerated $\left(4^{\circ} \mathrm{C}\right)$ storage. Int $\mathrm{J}$ Food Sci Tech, 51: 1130-1139

Luna LG, 1968. Manual of histologic staining methods of the Armed Forces Institute of Pathology, 3rd edn., McGraw-Hill, New York

Leygonie C, Britz TJ and Hoffman LC, 2012. Impact of freezing and thawing on the Quality of Meat: Review. Meat Sci, 91: 93-98

Pirestani S, Saharian M and Barzegar M, 2010. Fatty acids changes during frozen storage in several fish species from South Caspian Sea. J Agr Sci Tech, 12: 321-329

Popelka P, Nagy J, Pipová M, Marcinèák, S and Lenhardt L,2014. Comparison of chemical, microbiological and histological changes in fresh, frozen and double frozen rainbow trout (Oncorhynchus mykiss). Acta Vet Brno, 83: 157-161
Rathod N and Pagarkar A, 2013. Biochemical and sensory quality changes of fish cutlets, made from Pangasius fish (Pangasianodon hypophthalmus), during storage in refrigerated display unit at -15 to $-18{ }^{\circ} \mathrm{C}$. Int J Food Agri Vet Sci, 3 (1): 1-8

Strateva M and Penchev G, 2020. Histological, physicochemical and microbiological changes in fresh and frozen/thawed fish. Trakia J Sci, 1: 69-80

Thirugnanasambandam M, Iniyan S and Goic R, 2010. A review of solar thermal technologies. Renew Sustain Energy Rev, Elsevier, 14(1):312-322

Tinacci L, Armani A, Guidi A, Nucera D, Shvartzman D et al., 2018. Histological discrimination of fresh and frozen/thawed fish meat: European hake (Merluccius merluccius) as a possible model for white meat fish species. Food Control, 92: $154-161$

Wang D and Hsieh YHP, 2016. The use of imported pangasius fish in local restaurants. Food Control, 65: 136-142

Zhang X, Owens CM and Schilling MW, 2017. Meat: the edible flesh from mammals only or does it include poultry, fish, and seafood? Anim Front, 7(4): $12-18$ 